\title{
An Assessment of Physicochemical Parameters of Selected Industrial Effluents in Nepal
}

\author{
Abhinay Man Shrestha, ${ }^{1}$ Sanjila Neupane, ${ }^{1}$ and Gunjan Bisht ${ }^{2}$ \\ ${ }^{1}$ Department of Environment Science and Engineering, School of Science, Kathmandu University, Dhulikhel, Nepal \\ ${ }^{2}$ Department of Chemical Science and Engineering, School of Engineering, Kathmandu University, Dhulikhel, Nepal \\ Correspondence should be addressed to Gunjan Bisht; gunjanbisht31@gmail.com
}

Received 2 August 2017; Accepted 1 October 2017; Published 25 October 2017

Academic Editor: Wenshan Guo

Copyright (c) 2017 Abhinay Man Shrestha et al. This is an open access article distributed under the Creative Commons Attribution License, which permits unrestricted use, distribution, and reproduction in any medium, provided the original work is properly cited.

It is a well-known fact that the effluents released from the industries and environmental degradation go hand in hand. With the ongoing global industrialization this problem has been further aggravated. As such, Nepal is no exception. Hundreds of industries are being registered in the country annually which inevitably brings the issues regarding environmental pollution. This study has been conducted with samples of wastewater from 5 different industrial sites in 4 districts of Nepal, namely, Makwanpur, Sunsari, Morang, and Kathmandu, among which two were Waste Water Treatment Plants which treated the combined effluents collected from various sources. The other three sites were from wires and cables industry, paint manufacturing industry, and plastic cutting industry. The physicochemical parameters analysed were $\mathrm{pH}$, temperature, conductivity, turbidity, and $\mathrm{Cu}, \mathrm{Cr}, \mathrm{SO}_{4}{ }^{2-}$, and $\mathrm{PO}_{4}{ }^{3-}$ levels. Possible onsite measurements were recorded using portable, handheld devices whereas other parameters were assessed in the laboratory. The observed parameter levels in the collected samples were compared against the available Nepal national standards for industrial effluents and in the absence of standards for industrial effluents, with other relevant standard levels. Most of the parameters analysed were within the permissible limits with the exception of $\mathrm{pH}$ and Cr levels in some sites.

\section{Introduction}

Effluents released from the industries into water bodies can cause serious environmental degradation and deterioration; especially with the ongoing increase in the industrialization around the world, water pollution too is becoming rampant. It is reported that around $70 \%$ of the industrial wastes in the developing nations are disposed of untreated into waters thereby contaminating the existing water supplies [1]. In the state of Colorado, US, around 23,000 abandoned mines have been accredited for the pollution of as much as $2,300 \mathrm{~km}$ of streams [2].

Many studies conducted have highlighted this problem. Kaplay and Patode (2004) [3] observed that groundwater from the region of New Nanded, Maharashtra, India, demonstrated higher content of total dissolved solids (TDS), $\mathrm{Cl}$, Total Hydrocarbons ( $\mathrm{TH}), \mathrm{Ca}, \mathrm{Mg}$, and $\mathrm{SO}_{4}$, with the source of pollution being reported as effluents from the nearby industries. Similar results have been observed in the groundwater pollution due to the discharge of industrial effluents in Venkatapuram area, Andhra Pradesh, India [4]. It has been reported that, over the past few decades, the surface and groundwater of China have been considerably polluted owing to the discharge of industrial and municipal wastewaters, household wastes, and agricultural activities [5]. As per a national water quality survey in the country, water from about only $58.8 \%$ of major lakes, $64.2 \%$ of the river sections, and only $23.2 \%$ of the groundwater wells could meet the standard quality criteria of drinking water sources [6].

Meanwhile, Nepal has been witnessing some rapid urbanization and industrialization over the past few years. It is reported that Nepal is one of the fastest urbanizing countries in the world and for the period 2014-2050, it is expected that the country will continue to remain among the top ten fastest urbanizing countries in the world, with an expected urbanization rate (annual) of 1.9 percent [7]. As per the latest industrial statistics of the country, new industry registrations are increasing by the year with manufacturing industries 


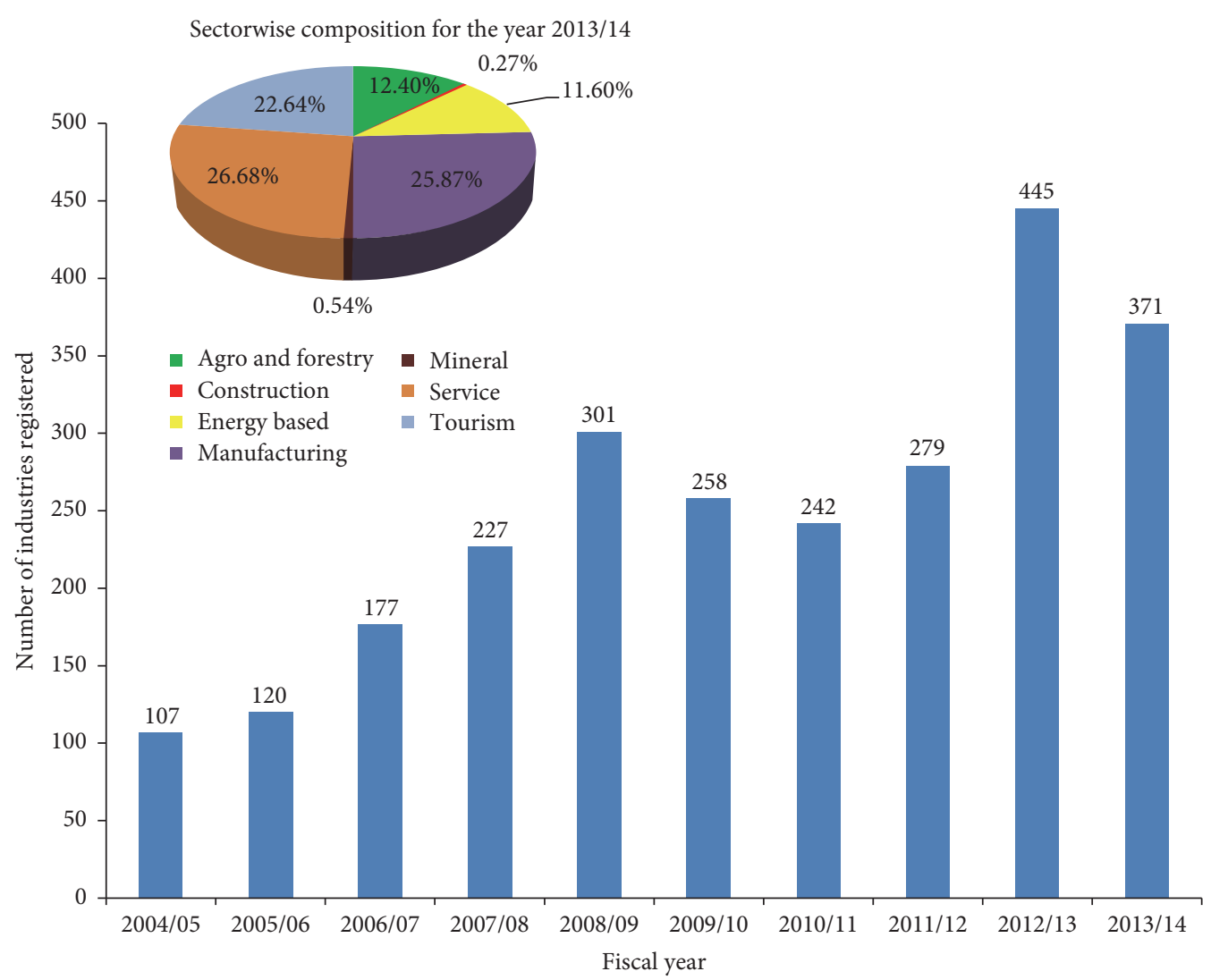

FIGURE 1: The increasing trend of industry registration in Nepal from the fiscal year 2004/05 to 2013/14, along with the sectorwise composition for the fiscal year 2013/14 (source: Department of Industry, GoN [8]).

TABLE 1: The categorization of the four industrial zones of Nepal.

\begin{tabular}{lcc}
\hline S number & Zone & Designation/specification \\
\hline$(1)$ & Zone 1 & Municipality areas within the Kathmandu Valley \\
$(2)$ & Zone 2 & Municipality areas outside the Kathmandu Valley \\
$(3)$ & Zone 3 & Municipality areas of Biratnagar, Dharan, Pokhara, Birgunj, Janakpur, Siddharthanagar, Butwal, and Nepalganj \\
$(4)$ & Zone 4 & Municipality areas other than those mentioned in Zone 3 \\
\hline
\end{tabular}

Source: Ministry of Industry and Ministry of Commerce and Supplies, GoN 2009 [9].

constituting a major portion $(25.87 \%)$ of the categorical composition of industries as highlighted by the data shown in Figure 1 [8].

Furthermore, majority of the industries and industrial regions are scattered in the hot Terai flatlands and Hilly mountainous belts of the country. Urban centres of the country's capitol Kathmandu Valley and other major cities as Biratnagar, Janakpur, Bhairahawa, Rajbiraj, Butwal, Nepalganj, and Hetauda harbour most of the industries. At present, the Government of Nepal (GoN) has established 11 Industrial estates, namely, Balaju, Patan, Bhaktapur, Hetauda, Pokhara, Dharan, Butwal, Nepalganj, Birendranagar, Rajbiraj, and Dhankuta [9], along with 4 industrial zones as specified in Table 1.

However, genuine voices are being raised regarding the fact that there is no effective or adequate study or strategy that addresses the positive and negative consequences that occur with such rapid urbanization and the water pollution caused by such industries and industrial activities in the country. Sah et al. (2002) [10] have studied the detrimental effects on fish and other aquatic organisms in the Narayani River due to the receiving effluents from several industries including pulp and paper mills and they found that considerable concentrations of heavy metals such as $\mathrm{Zn}, \mathrm{Cu}$, and $\mathrm{Cr}$ were found in the tissues of the fishes inhabiting in the river. Furthermore, according to an article published by a leading national daily of the country, The Himalayan Times (dated November 14, 2007) [11], a report made public by the Narayani Environment Conservation and Local Resource Management Centre highlighted that chemical wastes disposed into the Narayani River by the nearby located brewery and paper mills industries were leading to fluctuations in the temperatures of the river water, 

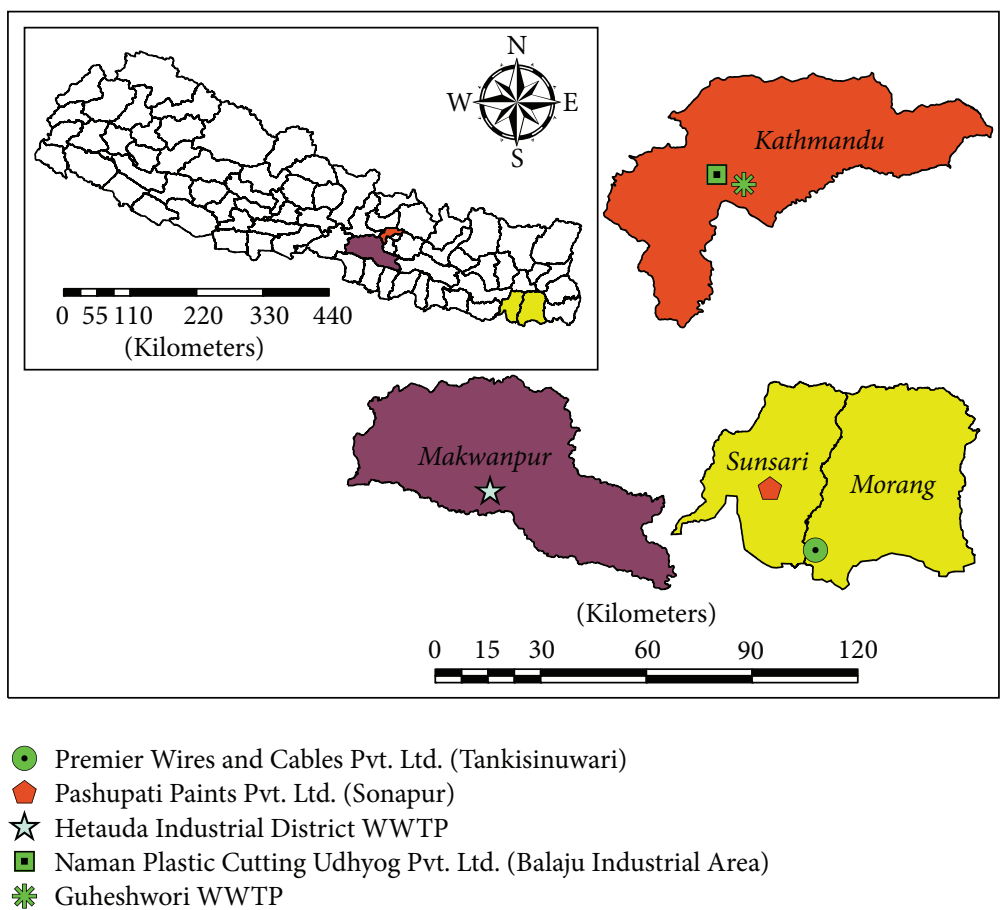

Figure 2: Five sites of this study (Sites 1, 2, 3, 4, and 5) present in 4 districts of Nepal (inset: map of Nepal showing the four districts as highlighted).

rise in the acidity, and reduction in the oxygen levels along with a corresponding rise in the nitrogen and phosphorus levels.

Neupane in 2003 [12] has reported that the Lumbini Sugar Mills released their effluents directly into the nearby Somnath stream. They analysed physicochemical parameters like temperature, $\mathrm{pH}$, acidity, alkalinity, hardness, free $\mathrm{CO}_{2}$, total solid matter, $\mathrm{DO}, \mathrm{N}, \mathrm{P}, \mathrm{K}, \mathrm{BOD}$, and COD in this contaminated stream water which was used for irrigation purposes and concluded that the crop productivity in those lands was relatively lower than on land irrigated with uncontaminated water.

Likewise, an assessment of the geochemical parameters of the water quality of Karra river, located near the Hetauda Industrial District, has highlighted that the pollution of the river was severe near the industrial stretches due to the direct discharge of the treated and untreated effluents from the industries. Certain samples have showcased a high $\mathrm{pH}$ of $>9.0$ which is reported to be detrimental and even lethal for the growth of amphibian larvae in the river. High conductivity levels (up to $2023 \mu \mathrm{S} / \mathrm{cm}$ ), high bicarbonate levels (up to $327 \mathrm{mg} / \mathrm{L})$, and silica levels $(14.8 \mathrm{mg} / \mathrm{L})$ were also reported to be found in the river [13].

Not many reports or studies have been published regarding the quality of industrial effluents of Nepal. The aforementioned studies are some of the few published literatures available regarding it. Hence, in the light of these issues, this study has been conducted in selected sites, among the different industrial regions of the country, to provide a further reach into assessing the various industries of Nepal and their effluent quality parameters.

\section{Materials and Methods}

2.1. Site Selection. Samples of wastewater were collected from 5 different sites in 4 districts of Nepal, namely, Makwanpur, Sunsari, Morang, and Kathmandu. Site 1 was an industrial Waste Water Treatment Plant (WWTP) located in Makwanpur which treated the combined effluents and wastewater from an industrial estate in the district. Site 2 was a paint manufacturing and processing plant located in Sunsari. Site 3 included wires and cables manufacturing industry located in Morang. The other two sites, Site 4 and Site 5, were from within the Kathmandu Valley. Site 4 was another WWTP that treated industrial along with municipal wastes within the valley whereas Site 5 included a plastic cutting industry located in the Balaju Industrial Estate. These sites have been showcased in Figure 2.

2.2. Sample Collection. A total of 6 samples were collected from Sites 1, 4, and 5 each, whereas 5 samples were collected from Sites 2 and 3 each. Sampling bottles and the preservative to be used $\left(\mathrm{HNO}_{3}\right)$ were provided by Environment and Public Health Organisation (ENPHO), Baneshwor, Nepal. For the purpose of onsite measurements, portable $\mathrm{pH}$ meter (Hanna S358236) and portable conductivity meter (HM Digital Aquapro Water Tester) were provided by the Department of Environmental Science and Engineering (DESE), Kathmandu University.

2.3. Parameter Analysis. The samples collected from the 5 sites were analysed for parameters differentiated into 3 categories, namely, physical parameters which included $\mathrm{pH}$, 
temperature, conductivity, and turbidity; heavy metal analysis of $\mathrm{Cu}, \mathrm{Cr}, \mathrm{Ni}$, and $\mathrm{As}$; and analysis of anions $\mathrm{SO}_{4}{ }^{2-}$ and $\mathrm{PO}_{4}{ }^{3-}$.

2.3.1. Determination of Physical Parameters. As stated earlier, $\mathrm{pH}$, conductivity, and temperature readings were taken directly in the field using the aforementioned portable, handheld devices. The turbidity analyses of the samples were conducted using turbidity meter Hanna HI98703-01 in the DESE Lab itself.

2.3.2. Determination of Heavy Metals. For the detection of heavy metals, the samples were sent to ENPHO Lab, to be detected using Atomic Absorption Spectroscopy (APHA, AWWA, WEF 2012, 3111 B) [14]. Detection for four heavy metals, namely, $\mathrm{Cu}, \mathrm{Cr}, \mathrm{Ni}$, and $\mathrm{As}$, was carried out where $\mathrm{Ni}$ and As levels in the samples were found to be below the detection limit of the instrument. Hence further analysis was done with the $\mathrm{Cu}$ and $\mathrm{Cr}$ concentrations in the samples.

2.3.3. Determination of Anions. The analysis for anions was conducted in the Quantitative Analysis Lab at the Department of Biotechnology, Kathmandu University. For the detection of sulphate, conditional reagent was prepared by mixing appropriate amounts of glycerol with a solution containing conc. $\mathrm{HCl}$, distilled water, ethanol (95\%), and sodium chloride. A standard solution of sulphate was prepared by dissolving anhydrous sodium sulphate in distilled water. A calibration curve was plotted taking various concentrations of the standard sulphate solution with specified amount of conditional reagent and analytical grade barium chloride crystals. The same procedure was conducted using the samples for the detection of sulphate in them. The absorbance was measured at $420 \mathrm{~nm}$ using GENESYS 10S UV-Vis Spectrophotometer [15].

For the detection of phosphates, conditional reagents were prepared by dissolving appropriate amounts of ammonium molybdate in distilled water; sodium sulphide; and diluted $(0.25 \mathrm{~N})$ sulphuric acid. Stock solution of phosphate was prepared by dissolving disodium hydrogen phosphate in distilled water (whose working solution was prepared by diluting this solution to an appropriate concentration with water). A calibration curve was plotted taking various concentrations of the standard phosphate solution with specified amount of conditional reagents and the procedure was also followed for the detection of phosphates in the samples by measuring the absorbance at $715 \mathrm{~nm}$ using GENESYS 10S UVVis Spectrophotometer [16].

\section{Results and Discussions}

3.1. Assessment of the Physical Parameters of the Industrial Effluents. The $\mathrm{pH}$ and turbidity levels observed in the samples of 5 sites of this study have been shown in Figure 3. As per the Environmental Conservation Regulations (ECR), 1997, formulated by the Government of Nepal, the tolerable

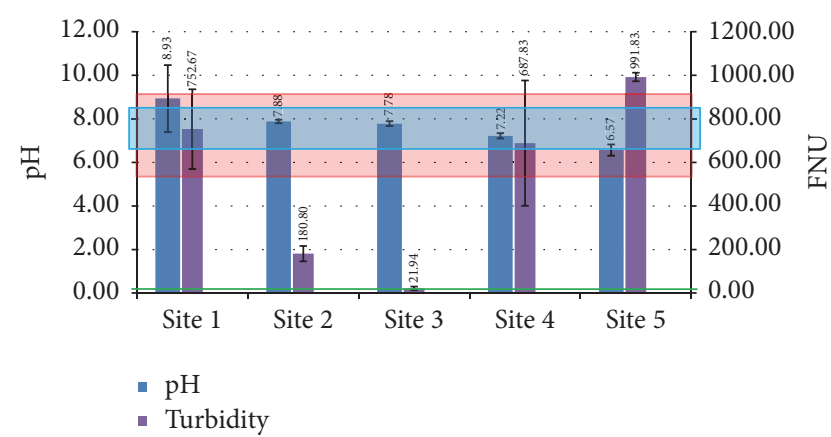

Figure 3: Graphs showing the $\mathrm{pH}$ and turbidity levels with their respective error bars on standard deviation, observed in the samples of 5 sites of this study, along with the ECR tolerable $\mathrm{pH}$ range (5.5-9) as shown by red rectangle, NDWQS $\mathrm{pH}$ range (6.5-8.5) as shown by blue rectangle, and NDWQS turbidity standard (10 FNU) as shown by green line.

limits for $\mathrm{pH}$ range from 5.5 to 9 for the industrial effluents [17], whereas the tolerable range as per the National Drinking Water Quality Standards (NDWQS) for rural surface water supply system is $6.5-8.5$ [18]. All the samples were found to have mean $\mathrm{pH}$ values within these limits except for samples of Site 1. The pH levels were found to be maximum in the samples from Site 1 with a mean value of 8.93 , slightly higher than the NDWQS limit of 8.5 , and the lowest in the samples from plastic cutting industry (Site 5) having a mean of 6.57. Regarding the turbidity levels, no standards for industrial levels as such were found; hence they were compared against the National Drinking Water Quality Standards which had set a turbidity standard of $10 \mathrm{FNU}$ for rural surface water supply systems [18]. Turbidity levels were found highest in the samples from Sites 5, 4, and 1 with mean values of $991.83 \mathrm{FNU}$, 752.67 FNU, and 687.83 FNU, respectively. Turbidity levels were found to be the lowest in Site 3 (cables and wire industries) having a mean of $21.94 \mathrm{FNU}$, as was evident from direct observation of the clear samples in the field itself. Turbidity levels are positively related to the Total Suspended Solids (TSS) [19]; hence it can be established that the samples from Sites 5, 4, and 1 had higher content of TSS in them. Among the samples, Sites 1 and 4 showed higher deviations from the mean. This could be attributed to the fact that these sites were WWTPs and therefore the influent that they received was not uniform in composition, given the large number of discharge sources and the change in the discharge composition by the minute, which would enter these WWTPs.

Figure 4 shows the conductivity and temperature levels observed in the samples of five sites of this study. As in the case of turbidity, there were no specific standards for the conductivity levels in industrial effluents. Hence, they were compared against the National Drinking Water Quality Standards which had set a conductivity standard of $1500 \mu \mathrm{S} / \mathrm{cm}$ for rural surface water supply systems [18]. The mean conductivity levels of all samples were below the tolerance limits. The conductivity levels too were found to be the highest in samples from Sites 1, 4, and 5 with 


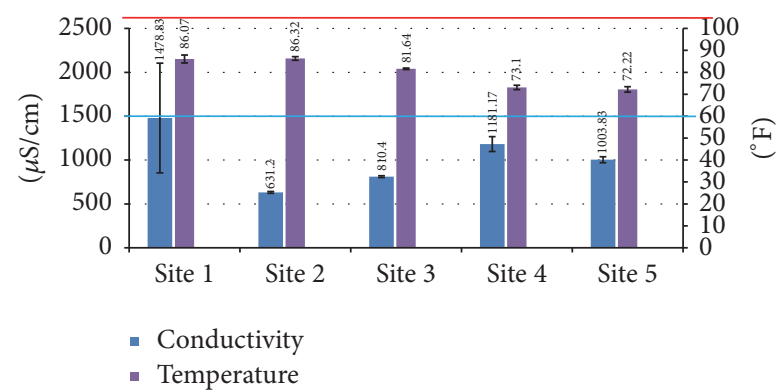

FIGURE 4: Graphs showing the conductivity and temperature levels with their respective error bars on standard deviation, observed in the samples of 5 sites of this study, along with the ECR tolerable limit for temperature $\left(104^{\circ} \mathrm{F}\right)$ as shown by red line and NDWQS tolerable limit for conductivity $(1500 \mu \mathrm{S} / \mathrm{cm})$ as shown by blue line.

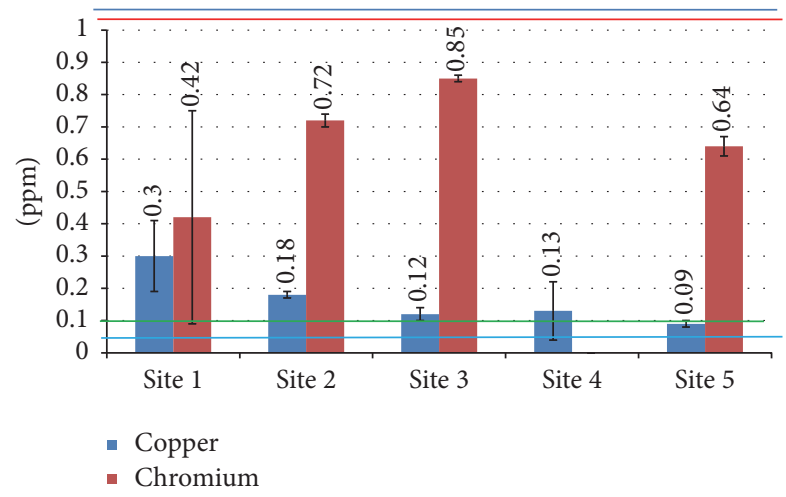

Figure 5: Graphs showing the copper and chromium levels with their respective error bars on standard deviation, observed in the samples of 5 sites of this study, along with the ECR tolerable limit for copper ( $3 \mathrm{ppm})$ as shown by red line, the ECR tolerable limit for chromium $(0.1 \mathrm{ppm})$ as shown by green line, and the NDWQS tolerable limit for chromium $(0.05 \mathrm{ppm})$ as shown by blue line.

means of $1478.83 \mu \mathrm{S} / \mathrm{cm}, 1181.17 \mu \mathrm{S} / \mathrm{cm}$, and $1003.83 \mu \mathrm{S} / \mathrm{cm}$, respectively. The conductivity levels are strongly related to the TDS levels [20]; hence it can be established that the samples from these sites contained high TDS contents given that these were effluents from a mixture of industries (as in the case of Site 1), wastewater sources (as in the case of Site 4), and plastic waste products (as in the case of Site 5). Furthermore, here too, significant deviations from the mean values can be seen in the samples from Sites 1 and 4, the reason being as mentioned previously. The temperature levels in all the samples were found to be significantly under the tolerance limit for industrial effluent standard $\left(40^{\circ} \mathrm{C}\right.$, i.e., $\left.104^{\circ} \mathrm{F}\right)$ as specified by Environment Conservation Regulations (ECR) 1997 [17].

3.2. Assessment of the Heavy Metals in the Industrial Effluents. Copper is found in chalcophile deposits along with other metals like $\mathrm{Pd}, \mathrm{Cd}, \mathrm{Zn}$, and so on, which are used in various industries like alloys, ceramics, and pesticides [21], and is also released from plumbing systems [22]. Figure 5 shows the copper and chromium levels observed in the samples. All the

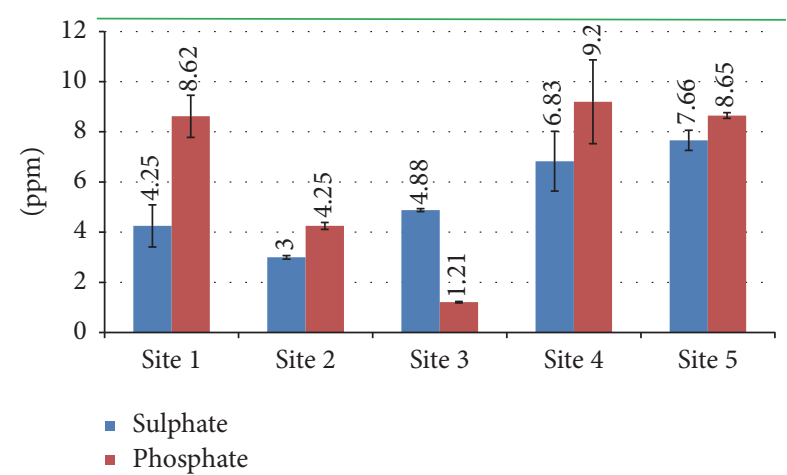

FIGURE 6: Graphs showing the sulphate and phosphate levels with their respective error bars on standard deviation, observed in the samples of 5 sites of this study, along with Nepal Gazette tolerance limit for sulphur (500 ppm) as shown by green line.

samples showed copper levels below the standard specified by Environment Conservation Regulations (ECR) 1997 [17]. The highest concentration (mean $0.3 \mathrm{ppm}$ ) was found in samples from Site 1 which can be attributed to the presence of the above-mentioned industries within the industrial estate. Copper can also be released into the environment from other industries as well such as chloralkali, electroplating, paints and dyes, pesticides, and fertilizers along with the disposal of municipal and industrial wastes [21]. Hence significant levels are found in samples from paint industry at Site 2 (mean $0.18 \mathrm{ppm}$ ) and the WWTP at Site 4 (mean $0.13 \mathrm{ppm}$ ). Regarding the presence of chromium in the samples, Sites 1, 2,3 , and 4 showed levels higher than the standard specified by the ECR 1997 [17], as well as the NDWQS standard for rural surface water supply [18]. From the samples, the highest concentration was found in wires and cables industry at Site 3 (mean $0.85 \mathrm{ppm}$ ) and paint industry at Site 2 (mean $0.72 \mathrm{ppm}$ ) which is supported by the fact that industrial activities like electroplating, metal cleaning and processing, and leather tanning are considered the major sectors that release chromium into the environment [23] and, furthermore, chromium is also used in paints and dying processes [24].

3.3. Assessment of Sulphate and Phosphate Levels in the Industrial Effluents. Figure 6 shows the sulphate and phosphate levels in the collected samples. In the absence of other industrial effluent standard for sulphate, the levels were compared against the Nepal Gazette tolerance limit for discharge of sulphate into public sewerage which is stated as $500 \mathrm{ppm}$ [25]. All the samples showed sulphate levels very well below this standard. The highest level of sulphate (mean $7.66 \mathrm{ppm}$ ) was found in the samples from plastic cutting industry (Site 5). This could be due to the abundance of ink cartridge wastes in the plastic waste samples as in such ink cartridges sulphate can be used in the form of barium sulphate as a filler material [26]. Furthermore, it is also reported that barium sulphate can also be used as additive in various plastic products [27]. Phosphate content is seen as the highest one in samples from Site 4 (mean $9.2 \mathrm{ppm}$ ), Site 5 (8.65 ppm), and 
Site $1(8.62 \mathrm{ppm})$. This can be attributed to the increased use of phosphates in the form of fertilizers for enhanced plant growth [28] and hence its high content in the municipal wastewater (Site 4 ) or its use in meat processing and poultry productions industries [29] and hence its high content in the industrial effluents (Site 1). Since there were no Nepal standards for phosphate levels in drinking or effluent waters, for comparison purposes the Indian Standard Institution levels for organic phosphates were used, which stated a limit of $100 \mu \mathrm{g} / \mathrm{L}$ (i.e., $0.1 \mathrm{ppm}$ ) in drinking water [30]. The samples of this study have shown levels exceeding this standard. Furthermore, a total phosphate-phosphorus value exceeding $0.1 \mathrm{mg} / \mathrm{L}$ (i.e., $0.1 \mathrm{ppm}$ ) is associated with eutrophication and natural water degradation [31]; hence such problems could arise if these effluents were to be released into the water bodies.

\subsection{Correlational Analysis for the Various Physicochemical} Parameters of the 5 Sites. The correlations for the various physicochemical parameters of the 5 sites have been tabulated in the form of a correlation matrix shown in Table 2. From the correlation matrix it can be seen that not much correlation was found among the various physicochemical parameters analysed. However, it can be observed that the temperature and conductivity readings were found to be positively correlated (as marked with asterisks) in all the samples. This could be explained as in an aqueous solution; with increase in the temperature, the components of the solution could undergo dissociation into their respective free ions which could then conduct electricity. Hence a positive correlation is obtained. Barron and Ashton in 2007 have observed similar results whilst studying various aqueous solutions [32]. Mandal in 2014 has also analysed the effect of temperature on the electrical conductivity of industrial effluents and has found similar trend, the reason being attributed to the decrease in viscosity associated with an increase in temperature [33].

There is also a positive correlation observed with the electrical conductivity and the presence of ions (copper, chromium, sulphate, and phosphate) in all the samples (as highlighted by green). The relation of electrical conductivity and the presence of ions have been highlighted in many studies $[34,35]$ which further supports the observed trend.

\section{Conclusion}

Samples of industrial effluents from 5 industrial regions in the country were collected and their physicochemical analysis was done. The levels were compared against the standards for industrial effluents as specified by the Environmental Conservation Regulations (ECR 1997) [17] and in the absence of the standards for the concerned parameter, with other relevant standards.

The mean $\mathrm{pH}$ levels of all the samples were found to be well within the tolerable range as specified by the Environmental Conservation Regulations (ECR) 1997 [17] and met the National Drinking Water Quality Standards (NDWQS) for rural surface water supply systems [18], with the exception of Site 1 which had mean $\mathrm{pH}$ values slightly higher than the drinking water quality standards as per the NDWQS. However, the turbidity levels were found to be immensely higher than the NDWQS [18]. Turbidity levels were found highest in samples from Sites 5, 4, and 1 and since turbidity levels are positively related to the Total Suspended Solids (TSS) [19], it can be established that the samples from Sites 5, 4, and 1 had higher content of TSS in them.

The mean conductivity levels in all samples were below the NDWQS for rural surface water supply systems [18]. The conductivity levels too were found to be the highest in samples from Sites 1, 4, and 5 and since conductivity levels are strongly related to the TDS (total dissolved solids) levels [20], it can be established that the samples from these sites contained high TDS content. The temperature levels in all the samples were found to be significantly under the tolerance limit for industrial effluent standard $\left(40^{\circ} \mathrm{C}\right.$, i.e., $\left.104^{\circ} \mathrm{F}\right)$ as specified by Environment Conservation Regulations (ECR) 1997 [17].

Copper levels were highest in the samples from Site 1 due to the presence of copper releasing industries within the industrial estate. However, overall, copper levels were found to be well below the ECR standard (Bhandari 2014) [17] in all 5 samples. Chromium levels were found to be exceeding the ECR standard [17] in 4 sites, namely, 1, 2, 3, and 4, as well as the NDWQS for rural water supply [18]. Chromium was found to be the highest in samples from the wires and cables industry at Site 3 and the paint manufacturing industry at Site 2. Significant chromium concentrations were not observed in samples from Site 4. Furthermore, sulphate levels in all 5 sites' samples were well under the Nepal Gazette tolerance limit for discharge of sulphate into public sewerage which is stated as $500 \mathrm{ppm}$ [25]. Sulphate levels were highest in samples from the plastic cutting industry at Site 5, the reason being attributed to the use of barium sulphate as additive in various plastic products $[26,27]$. Phosphate contents in all the samples were found very well exceeding the ISI limits for organic phosphate in drinking water [30] with the highest one in samples from Sites 4,5 , and 1 , the reason being attributed to the increased use of phosphates in the form of fertilizers [28] and in meat processing and poultry production industries [29].

It should be noted here that the levels of parameters showed higher deviations from the mean in samples from Sites 1 and 4 which could be attributed to the fact that these sites were WWTPs and therefore the influent that they received was not uniform in composition; hence the deviations observed in the parameter levels are as such. Also, the samples showcased positive correlation between temperature and conductivity levels as was supported by other studies as well [32, 33] along with positive correlation between the electrical conductivity and the presence of ions as was supported by other studies $[34,35]$.

This study was conducted to give a brief outlook into the various industries and their effluents in Nepal. The variability of physicochemical parameters analysed was limited by the budgetary concerns and time constraints. However, this study can provide a base and a direction towards a broad and perhaps a more detailed inspection of the various industries 


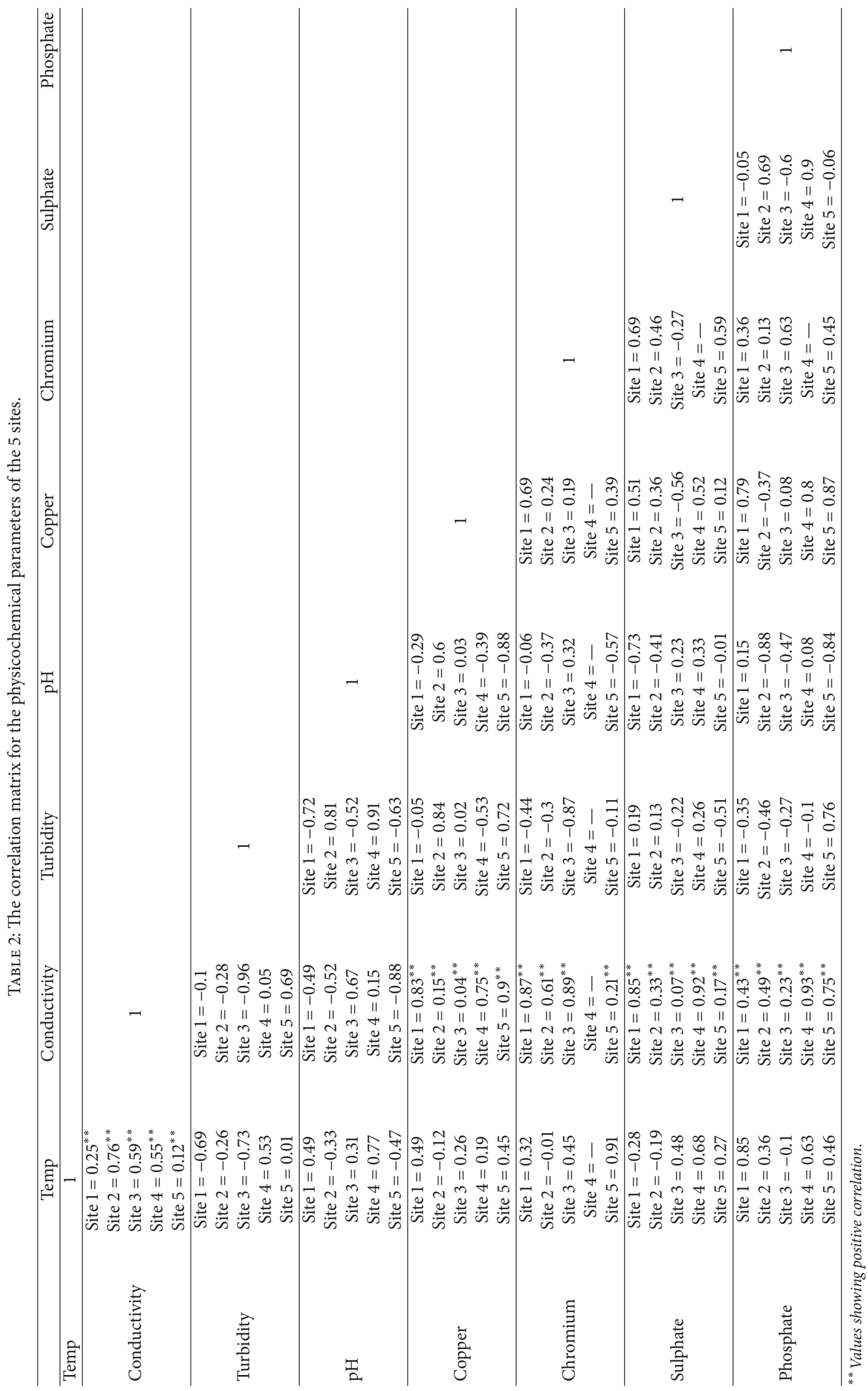


and its effluents in the country in the near future if the limitations as aforementioned were to be curtailed.

\section{Conflicts of Interest}

The authors declare that they have no conflicts of interest.

\section{Acknowledgments}

The authors acknowledge University Grant Commission of Nepal for funding this research.

\section{References}

[1] UN-Water, "World Water Day brochure," 2009, http://www .unwater.org.

[2] Pacific Institute, "World Water Quality Facts and Statistics," 2010, http://www.pacinst.org.

[3] R. D. Kaplay and H. S. Patode, "Groundwater pollution due to industrial effluent at Tuppa, New Nanded, Maharashtra, India," Environmental Geology, vol. 46, no. 6-7, pp. 871-882, 2004.

[4] N. Subba Rao, V. V. S. Gurunadha Rao, and C. P. Gupta, "Groundwater pollution due to discharge of industrial effluents in Venkatapuram area, Visakhapatnam, Andhra Pradesh, India," Environmental Geology, vol. 33, no. 4, pp. 289-294, 1998.

[5] J. Liu and J. Diamond, "China's environment in a globalizing world," Nature, vol. 435, no. 7046, pp. 1179-1186, 2005.

[6] Y. Hu and H. Cheng, "Water pollution during China's industrial transition," Environmental Development, vol. 8, no. 1, pp. 57-73, 2013.

[7] S. Bakrania, "Urbanisation and Urban Growth in Nepal," GSDRC Helpdesk Research Report, p. 1294, 2015.

[8] Department of Industry, Ministry of Industry, GoN. Industrial Statistics Fiscal Year 2070/071(2013/2014).

[9] Ministry of Industry (MoI) and Ministry of Commerce and Supplies (MoCS), NEPAL: Foreign Investment Opportunities, Enhancing Nepal's Trade-Related Capacity (ENTRec) project UNDP-Nepal, Nepal, South Asia, 2009.

[10] S. K. Sah, P. Acharya, and V. A. Lance, "Effect of Industrial Pollution on Fish in the Narayani River, Central Nepal," Nepal Journal of Science and Technology, vol. 4, pp. 5-14, 2002.

[11] The Himalayan Times, (dated 14th November, 2007), Industrial chemical wastes polluting Narayani river - by Chintamani Poudel, https://thehimalayantimes.com/nepal/industrial-chemical-wastes-polluting-narayani-river/.

[12] R. P. Neupane, Effect of Industrial Effluents on Agricultural Crops and Soil [Dissertation, thesis], A Dissertation submitted for the partial fulfilment of the requirements for the Master of Science in Botany, Kathmandu, Nepal, South Asia, September 2003.

[13] S. P. Kayastha, "Geochemical Parameters of Water Quality of Karra River, Hetauda Industrial Area, Central Nepal," J. of Inst. of Sci. and Tech, vol. 20, no. 2, pp. 31-36, 2015.

[14] APHA, AWWA, and WEF, Standard Methods for Examination of Water and Wastewater, American Public Health Association, Washington, DC, USA, 22nd edition, 2012.

[15] S. A. B. Mussa, H. S. Elferjani, F. A. Haroun, and F. F. Abdelnabi, "Determination of Available Nitrate, Phosphate and Sulfate in Soil Samples," Int. J. of PharmTech Research, IJPRIF, vol. 1, no. 3, pp. 598-604, 2009.
[16] M. M. S. Yogendra Kumar, M. S. Abdul Galil, M. S. Suresha, M. A. Sathish, and G. Nagendrappa, "A simple spectrophotometric determination of phosphate in sugarcane juices, water and detergent samples," E-Journal of Chemistry, vol. 4, no. 4, pp. 467-473, 2007.

[17] G. Bhandari, "A Review of Urban Water Reuse - Limits, Benefits and Risks in Nepal," International Journal of Geology, Agriculture and Environmental Sciences, vol. 2, no. 1, 2014.

[18] Ministry of Physical Planning and Works, "National Drinking Water Quality Standards, 2005 Implementation Directives for National Drinking Water Quality Standards," GoN, 2005, http:// mowss.gov.np/assets/uploads/files/NDWQS_2005_Nepal.pdf.

[19] L. H. X. Daphne, H. D. Utomo, and L. Z. H. Kenneth, "Correlation between Turbidity and Total Suspended Solids in Singapore Rivers," J. of Wat. Sust, vol. 1, no. 3, pp. 55-64, 2011.

[20] N. S. Ali, K. Mo, and M. Kim, "A case study on the relationship between conductivity and dissolved solids to evaluate the potential for reuse of reclaimed industrial wastewater," KSCE Journal of Civil Engineering, vol. 16, no. 5, pp. 708-713, 2012.

[21] A. K. Shrivastava, "A Review on Copper Pollution and its Removal from Water Bodies by Pollution Control Technologies," Indian Journal of Environmental Protection, vol. 29, no. 6, pp. 552-560, 2009.

[22] G. R. Calle, I. T. Vargas, M. A. Alsina, P. A. Pasten, and G. E. Pizarro, "Enhanced copper release from pipes by alternating stagnation and flow events," Environmental Science \& Technology, vol. 41, no. 21, pp. 7430-7436, 2007.

[23] A. A. Belay, "Impacts of chromium from tannery effluent and evaluation of alternative treatment options," Journal of Environmental Protection, vol. 1, no. 1, pp. 53-58, 2010.

[24] J. Guertin, C. Avakian, and J. Jacobs, "Overview of Chromium (VI) in the Environment: Background and History", in Chromium (VI) Handbook, pp. 1-21, CRC Press, Florida, Fla, USA, 2004.

[25] Central Bureau of Statistics (2014), Environmental Statistics of Nepal 2013, CNN Printing Press, Kathmandu, Nepal, South Asia, 2014, GoN.

[26] M. Ellila, The Use of Barium Sulphate in Printing Inks as Filler Material, Bachelor of Engineering Thesis, Helsinki Metropolia University of Applied Sciences, Helsinki, Finland, 2011.

[27] COWI, "Hazardous substances in plastic materials," Prepared in cooperation with Danish Technological Institute, 2013, http:// www.miljodirektoratet.no/old/klif/publikasjoner/3017/ta3017 .pdf.

[28] S. H. Chien, L. I. Prochnow, and H. Cantarella, "Recent developments of fertilizer production and use to improve nutrient efficiency and minimize environmental impacts," Advances in Agronomy, vol. 102, pp. 267-322, 2009.

[29] N. H. Bach Son Long, R. Gál, and F. Buňka, "Use of phosphates in meat products," African Journal of Biotechnology, vol. 10, no. 86, pp. 19874-19882, 2011.

[30] M. Kumar and A. Puri, "A review of permissible limits of drinking water," Indian Journal of Occupational and Environmental Medicine, vol. 16, no. 1, pp. 40-44, 2012.

[31] Water Research Center, "Phosphates in the Environment," http://www.water-research.net/index.php/phosphates.

[32] J. J. Barron and C. Ashton, "The effect of temperature on conductivity measurement," TSP, vol. 7, no. 3, 2007, https://www .reagecon.com/pdf/technicalpapers/Effect_of_Temperature_TSP07_Issue3.pdf. 
[33] H. K. Mandal, "Effect of temperature on electrical conductivity in industrial effluents," Recent Research in Sci and Tech, vol. 6, no. 1, pp. 171-175, 2014.

[34] H. Golnabi, M. R. Matloob, M. Bahar, and M. Sharifian, "Investigation of electrical conductivity of different water liquids and electrolyte solutions," Iranian Physical Journal, vol. 3, no. 2, pp. 24-28, 2009.

[35] C. P. Helito, M. K. Demange, and M. B. Bonadio, "Electrical Conductivity of Potassium salt- dimethylsulfoxide-water systems at different temperatures," Proc. of the Yerevan State Univ. Chemistry and Biology, vol. 1, pp. 3-6, 2013. 

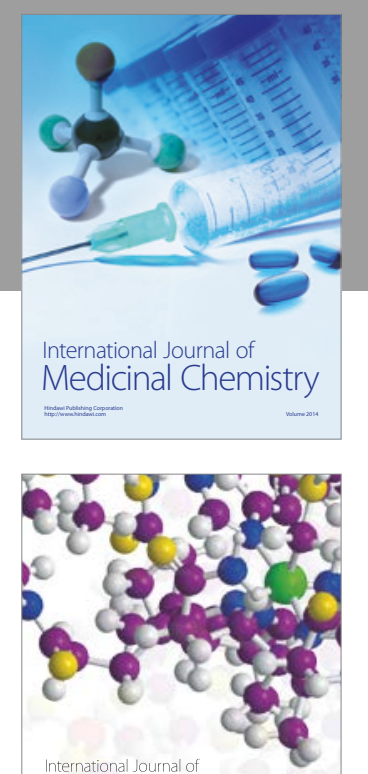

Carbohydrate Chemistry

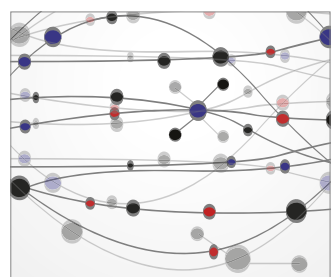

The Scientific World Journal
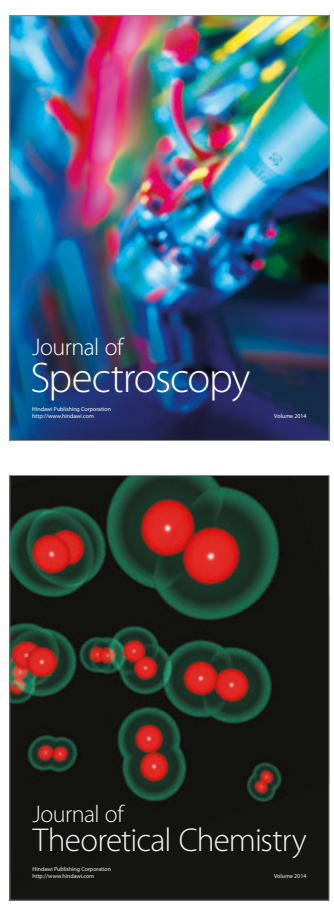
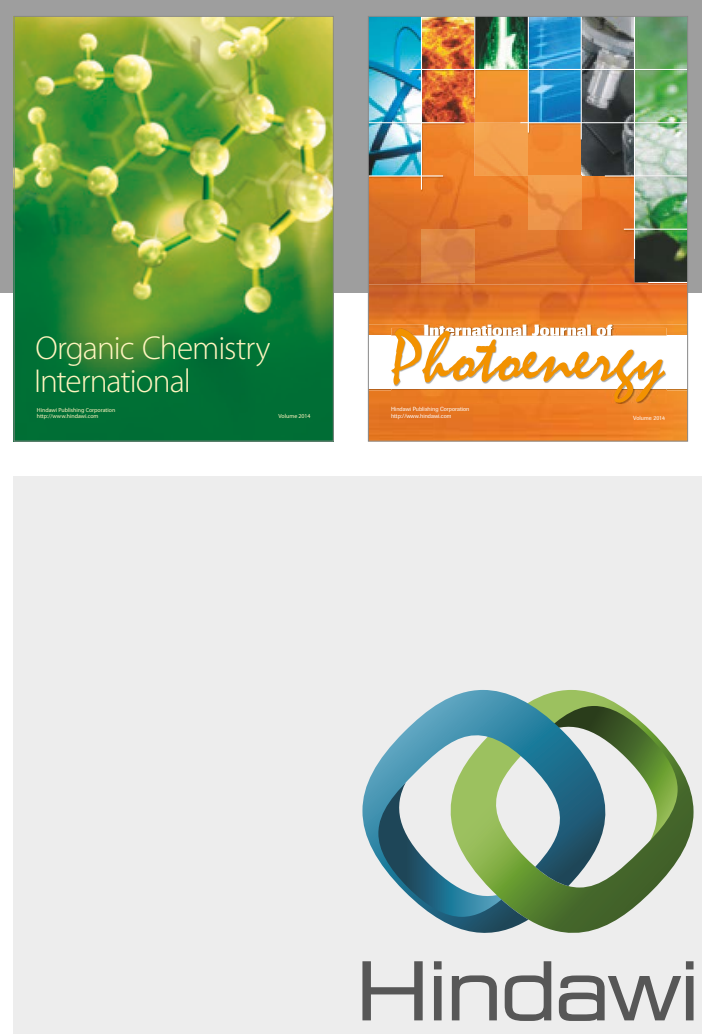

Submit your manuscripts at

https://www.hindawi.com

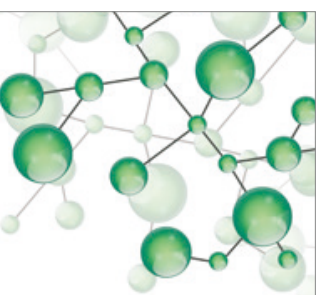

International Journal of

Inorganic Chemistry

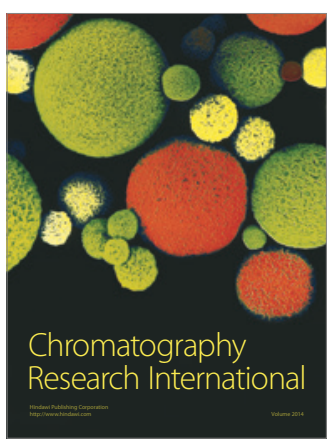

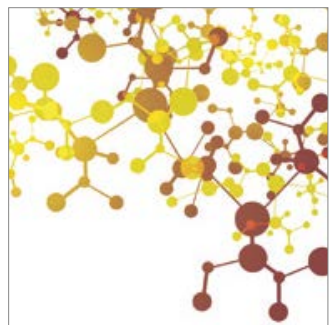

Applied Chemistry
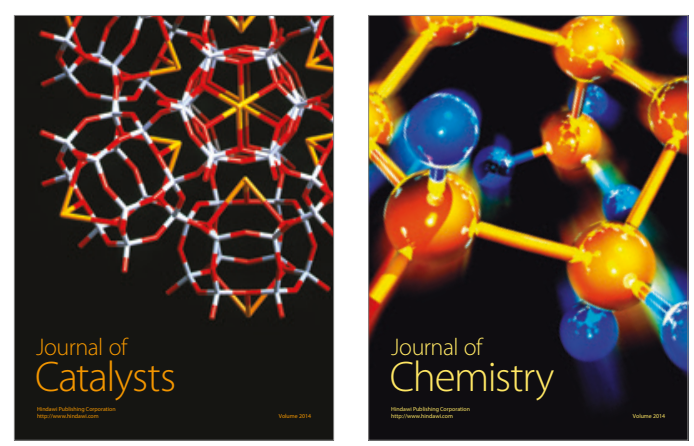
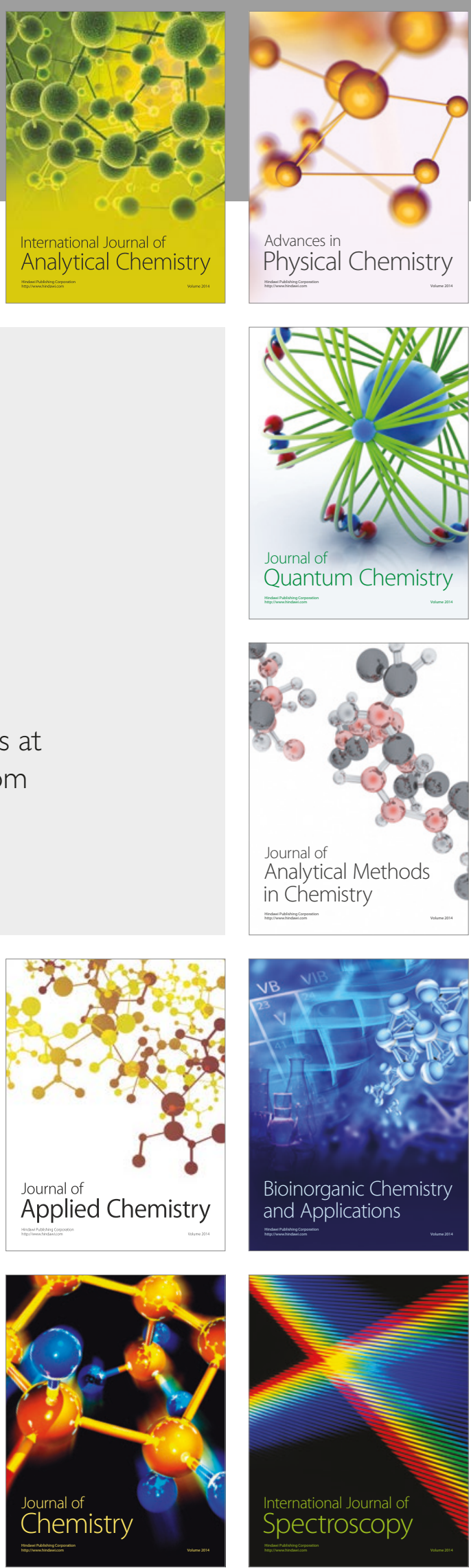